\title{
Quasi-Two-Dimensional Current Visualization by Locally One Dimensional Method
}

\author{
Shusuke MABUCHI ${ }^{\circ}$, Seiji HAYANO, Yoshifuru SAITO and Kiyoshi HORII
}

\begin{abstract}
In this paper, we propose a visualization method of the quasi-two-dimensional (2D) current distribution by locally one dimension (1D) method.

At first, we measure a perpendicular magnetic field to a current distributing surface, and estimate current distribution by using the two-dimensional inverse analysis.

Second, we estimate the $1 \mathrm{D} \mathrm{X}$ and $\mathrm{Y}$ current components from the $1 \mathrm{D}$ measured $\mathrm{X}$ and $\mathrm{Y}$ magnetic fields by using the $1 \mathrm{D}$ inverse analysis, respectively.

Finally, after convolving among the $2 \mathrm{D}$ and locally $1 \mathrm{D}$ current vectors, it is possible to evaluate the quasi-2D current distribution. As a result, it is found that more detailed current visualization than those of $2 \mathrm{D}$ inverse analysis is possible by convolution among the $1 \mathrm{D}$ and $2 \mathrm{D}$ current vectors.
\end{abstract}

Keywords : Visualization, Quasi-two-dimensional current distribution, Locally-one-dimensional method

\section{1. まえがき}

近年, 電気電子回路製造技術の急速な発展に伴い, プ リント基板配線が広汎に使われ，電気電子機器の信頼 性・性能が飛躍的な向上を遂げているのみならず，電気 電子機器のコンパクト化・スリム化がなされた.

プリント基板上の電流分布の可視化は, メンテナンス や，検査，電子デバイスの EMC 問題を検討するにあた り非常に重要かつ有用である。その電流情報を装置・デ バイスを解体，または破壊せずに求めるためには逆問題 を解かなければならない。

逆問題とは一般に不適切な線形システムを解くことに 帰する。不適切なシステムとは解が一意的に求まらない か, 解が存在しないものであり，そのため，さまざまな 手法によりシステム行列を構成し，拘束条件を付加する ことで近似解を導くものである.1)

本論文は, 従来の 2 次元電流探査では捕らえられない 詳紐な電流分布推定を可能とする局所 1 次元化法を提案 し，その有効性について考察するものである.

\section{2，逆問題的電流分布推定}

\section{1 放射磁界の測定と電流分布推定}

磁界源である電流分布の推定において最大の課題は, 放射磁界の測定方法と電流分布の推定方法に分類される. 磁界源である電流から生ずる磁界分布は理論上無限遠点 にまで分布するため, 磁界分布の測定は限られた局所的
な空間でなされる，しかしながら，磁界を生ずる磁界源 の分布する空間は無限に存在し得る. 従って, 局所的な 情報から現実に存在する情報源を求める必要がある.

\section{2 ループ電流モデル}

ここではFig. 1 に示すように，ある平面導体に分布す る電流密度 $\mathrm{J}$ を平面導体上の磁界 $\mathrm{H}$ を測定することによ って求める問題を考える。

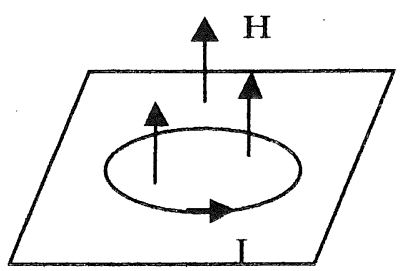

Fig. 1 Loop current $J$ and magnetic field $\mathrm{H}$

変位電流密度 $\partial \mathrm{D} / \partial \mathrm{t}$ が無視できる系で, 電流密度 $\mathrm{J}$ は 磁界 Hと次式で関係づけられる。

$\nabla \times \mathbf{H}=\mathrm{J}$

従って, 電流密度 $\mathrm{J}$ は必ず次式を満足しなければなら ない。

$\nabla \cdot \nabla \times \mathrm{H}=\nabla \cdot \mathrm{J}=0$

(2)式の関係はキルヒホッフの節点則と等価であり, 電 流密度を面積について積分したある点に流入する電流 $\mathrm{i}$ は流出電流と等しいことを意味する.（2)式を自動的に満 足する電流の一例はFig. 1 に示す環状に循環するループ 電流 i である.これは環状導体の何れの部分でも必ず入 
る電流と出る電流が等しいことに起因する.ここでは推 定される電流が Fig. 2 に示すループ電流でモデル化され ると仮定する.

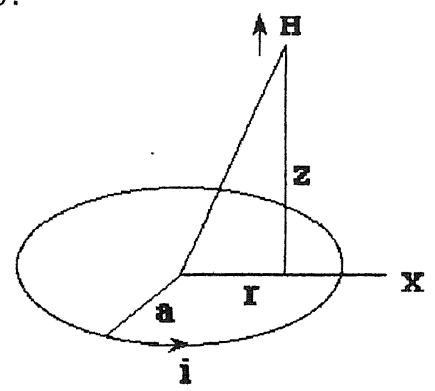

Fig. 2 Loop current $\mathrm{i}$ makes $\mathrm{z}$ axes magnetic Field $\mathrm{H}$

Fig. 2 のループ電流 $\mathrm{i}$ が与える $\boldsymbol{z}$ 軸方向の磁界 $\mathrm{H}_{\mathrm{z}}$ は(3) 式で与えられる.これはループ電流 $\mathrm{i}$ が与えられれば, ループの中心からループ面に沿った距離 $\mathrm{r}$, ループ面から

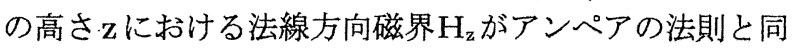
様な形(3)式で計算できることを意味する.

$$
\begin{aligned}
& H_{r}=\frac{1}{2 \pi}\left[\frac{1}{\sqrt{(a+r)^{2}+z^{2}}}\right]\left[\frac{a^{2}+r^{2}+z^{2}}{(a-r)^{2}+z^{2}} E(\kappa)+K(\kappa)\right] \\
& H_{z}=\frac{1}{2 \pi}\left[\frac{z}{\sqrt{(a+r)^{2}+z^{2}}}\right]\left[\frac{a^{2}-r^{2}-z^{2}}{(a-r)^{2}+z^{2}} E(\kappa)+K(\kappa)\right] \\
& \kappa^{2}=\frac{4 r a}{(r+a)^{2}+z^{2}}
\end{aligned}
$$

デカルト座標系で磁界の $\boldsymbol{x}, \boldsymbol{y}$ 方向成分 $\mathrm{H}_{\mathrm{x}}, \mathrm{H}_{\mathrm{y}}$ は(3) 式を用いて，(4)式で表せる。

$$
\begin{aligned}
& H_{x}=H_{r} \cos \theta=H_{r} \frac{x}{\sqrt{x^{2}+y^{2}}} \\
& H_{y}=H_{r} \sin \theta=H_{r} \frac{y}{\sqrt{x^{2}+y^{2}}} .
\end{aligned}
$$

Fig. 2 のループ電流を微小ループ電流モデルに置き換 える. 電流の分布する対象導体をFig. 3 に示すように微 小長方形に分割し, 分割された微小長方形中を還流する 電流ループを仮定する.

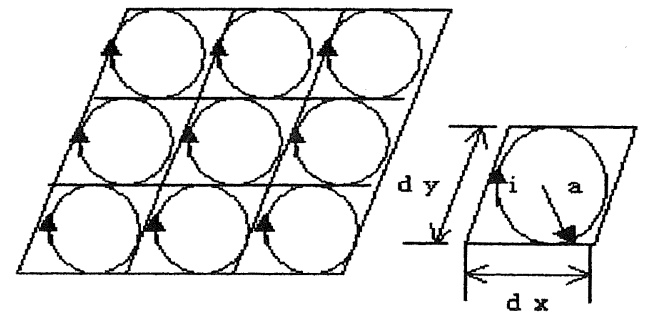

Fig. 3 consider of microscopic loop model

Fig. 3 の微小長方形中を循環する電流を同図中に示す円 形ループで置き換える. 円形ループの半径は(5)式によっ て決める.（5)式で決まるループ半径 a は微小長方形で縦 横比が等しい正方形に内接する円を意味する.この場合, 問題対象全体を通して各正方形の中心とモデルループの
中心が一致し，最も良い近似となる．縦横比が異なる微 小長方形では，各長方形の中心と(5)式で決まる半径を持 つループの中心を一致させることから問題全体の形状を 正方形に変形して考えることになる. 従って，ループ電 流分布モデルを適用する場合，分割された微小領域は正 方形とすべきである．これは，例えば問題対象が長方形 の場合、縦と横で分割数を変えることで実現される.

$$
a=\sqrt{\left(\frac{d x}{2}\right)\left(\frac{d y}{2}\right)}
$$

遒体上の磁界測定点と各ループの中心が一致するよう に対象を分割しループ電流モデルを適用すると，システ ム方程式は次のように与えられる。

$$
\mathbf{X}=D \mathbf{Y}
$$

または

$$
\left[\begin{array}{c}
x_{1} \\
x_{2} \\
\vdots \\
x_{n}
\end{array}\right]=\left[\begin{array}{cccc}
d_{11} & d_{12} & \cdots & d_{1 n} \\
d_{21} & d_{22} & \cdots & d_{2 n} \\
\vdots & \vdots & \ddots & \vdots \\
d_{n 1} & d_{n 2} & \cdots & d_{m n}
\end{array}\right]\left[\begin{array}{c}
y_{1} \\
y_{2} \\
\vdots \\
y_{n}
\end{array}\right]
$$

$\mathbf{X}, \mathbf{Y}, D$ はそれぞれ測定磁界を要素とするべクトル，ル 一プ電流の振幅を要素とするベクトル，そして(3)式，(4) 式から得られる係数を要素とするシステム行列である. システム行列 $D$ の逆行列を求めることが可能であれば, 各ループ電流が計算できる.ループ電流は閉じた経路を 流れているから，隣接するループ電流は差になる．よっ てループ電流分布の等高線に沿った形で流れていること になる. 従って, ループ電流分布に対して回転演算をす ることで対象導体上の電流ベクトル分布を得ることがで きる。

2.3 重み付き逆行列(Weighted Inverse Matrix, WIM)法 逆問題の多くは，局所的な情報に対応する式の数より も多い情報源に対応する未知数の数を持つ線形システム を解くことに帰する．換言すれば，逆問題のシステム方 程式は式の数よりも未知数の数が多い連立方程式である. このような線形システムは, システム行列が長方行列で あるため逆行列が計算できない. このため, 逆問題のシ ステム方程式は不適切な線形システムと乎ばれ，従来の 線形空間論では何らかの拘束条件を適用しない限り一意 的な解が得られない.

数学的には不適切な線形システムを解く方法として 一般化逆行列法が知られている. 一般化逆行列法の一種 である最小ノルム法は逆問題型の不適切な線形システム の解を与える一方法である. 最小ノルム法の最大の長所 は必ず解が得られる点にある。しかしながら，得られた 解が物理的に存在するとは限らず何らかの拘束条件を付 加しない限り実用的結果恃期待できない。

一般に逆問題は, 式の数より未知数の多い不適切なシ ステム方程式を解くことに帰する．ここでは，具体的な 例として次式を考える.

$a x+b y=c$ 


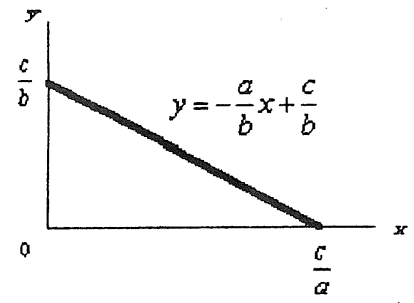

Fig. 4 Solution line of (7)

(7)式で, $x=0$ のとき $y=c / b, y=0$ のとき $x=c / a$ であるか ら,Fig. 4 に示す解直線上の点はすべて(7)式の解である.

$$
y=-\frac{a}{b} x+\frac{c}{b}
$$

(8)式は解直線を表し, 解は $\boldsymbol{x}$ が決まれば $y$ が決まるこ とを意味する．換言すれば， $\boldsymbol{x}, y$ の何れか一方が決まれ ば他は従属して決まる。これは重要な関係であり，逆問 題では, 式の数に等しい数の解が一意的に決まれば残り の解は従属して決まることを意味する。

いま， $\boldsymbol{x}, \boldsymbol{y}$ が次式で与えられるとする。

$$
\left[\begin{array}{l}
x \\
y
\end{array}\right]=\left[\begin{array}{l}
w_{1} \\
w_{2}
\end{array}\right] s_{0}
$$

ここで $w_{1}, w_{2}$ は重み係数であり， $s_{0}$ は定数である.

(9)式を(7)へ代入すれば,

$$
\left[\begin{array}{ll}
a & b
\end{array}\right]\left[\begin{array}{l}
w_{1} \\
w_{2}
\end{array}\right] s_{0}=[c]
$$

であるから，

$$
s_{0}=\left[w_{1} a+w_{2} b\right]^{-1}[c]
$$

として解ベクトルが得られる.（11)式を一般的に書けば

$$
\mathbf{X}=W[C W]^{-1} \mathbf{Y}
$$

(12)式で，X，Y， $C$ は，それぞれ $m$ 次の解ベクトル， $n$ 次の既知ベクトル，さらに $n$ 行 $m$ 列のシステム行列で ある. $W$ は $m$ 行 $n$ 列の重み行列である. $m>n$ を前提条 件にしている.

(12)式で最大の問題点は重み行列 $W$ の決め方である. ここでは解 $\mathrm{s}$ が解空間 $\alpha$ の関数 $\mathrm{s}(\alpha)$ であり，

$$
s(a)=s_{0}+a s_{1}+a^{2} s_{2}+\cdots+a^{n-1} s_{n-1}
$$

とした一例を示す.

(13)式から解ベクトル X の要素が $\Delta \alpha$ 毎に離散化され た值とすれば,

$\mathbf{X}=\left(\begin{array}{c}x_{1} \\ x_{2} \\ \vdots \\ x_{m}\end{array}\right)=\left(\begin{array}{ccccc}1 & 0 & 0 & \cdots & 0 \\ 1 & \Delta \alpha & \Delta \alpha^{2} & \cdots & \Delta \alpha^{n-1} \\ \vdots & \vdots & \vdots & \ddots & \vdots \\ 1 & (n-1) \Delta \alpha & {[(n-1) \Delta \alpha]^{2}} & \cdots & {[(n-1) \Delta \alpha]^{n-1}}\end{array}\right)\left(\begin{array}{c}s_{0} \\ s_{1} \\ \vdots \\ s_{n-1}\end{array}\right)=W \mathbf{S}$

で与えられる.

(14)式は解がテイラー級数展開可能として仮定した重 み行列 $W$ を決定する一方法である。すなわち，WIM (Weighted Inverse Matrix)法恃解が滑らかでテイラー 展開可能であり，且つ最初の第 $n$ 項までの和で解が表さ れると仮定することが骨子である．2）

\section{2 次元重みつき逆行列法による電流分布推定}

Fig. 5 に示す $20 \mathrm{~cm} \times 20 \mathrm{~cm}$ のモデル電流面に垂直な $z$ 方向磁界から 2 次元 WIM 法を用いて電流分布を推定す る.

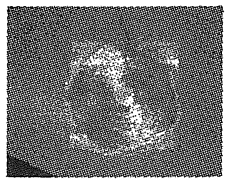

Fig. 5 Model current

モデル電流上の $n=5 \times 5=25$ 点の測定点で $z$ 方向磁界を 測定する. それらの值から，ターゲットの分割個数 $m=15$ $\times 15=225$ 点のループ電流を求める問題を考える.

Fig. 6 に測定された $z$ 方向磁界を示す. 磁界の湧き出 しと吸い込みを濃淡で表示している.

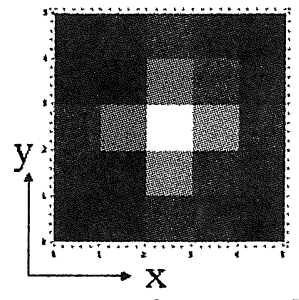

Fig. 6 Measured magnetic field in a direction of $z$ axis

Fig. 6 の磁界分布から 2 次元 WIM 法を用いて電流分 布を推定する.Fig. 7 は 2 次元 WIM 法によるループ電流 分布と電流べクトル分布の計算結果を示す.
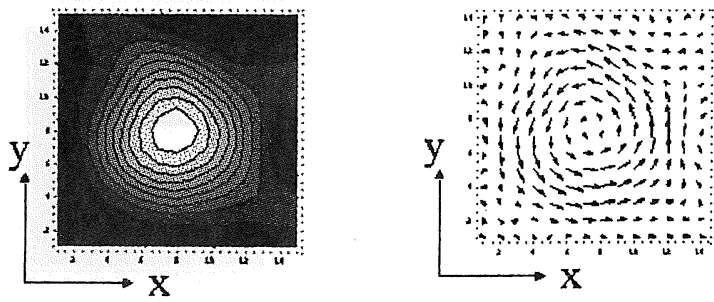

Fig. 7 Computed 2D current distribution

また，円電流の中心と測定面の中心をずらして測定され た磁界分布をFig. 8 に示す. Fig. 8 から電流分布を 2 次 元 WIM 法で推定した結果をFig. 9 に示す.

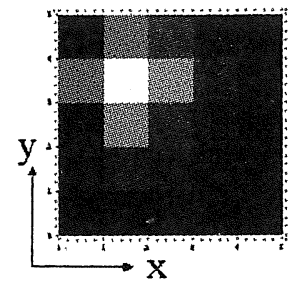

Fig. 8 Measured magnetic field in a direction of $z$ axis 

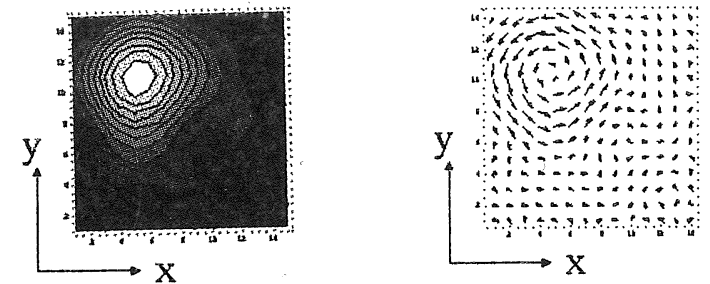

Fig. 9 Computed two-dimension current distribution

Fig. 7，9 ともにほぼ同じ電流分布図が得られている. 次に解の収束状況をFig. 10 に示す.

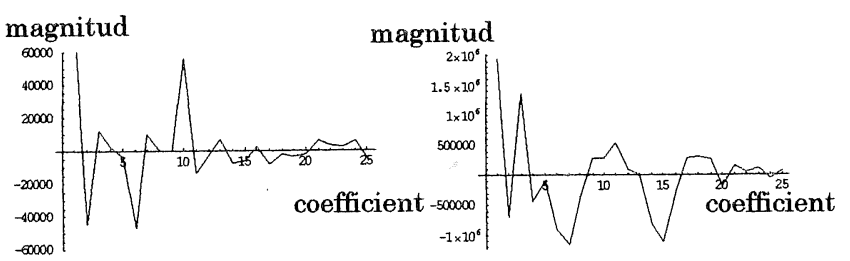

Located at center Located left up

Fig. 10 Convergence properties of the WIM solutions

Fig.10から，何れの解も(13)式の係数が収束している のがわかる.よって，2 次元 WIM 法は有効であるとい える.

\section{4. 局所 1 次元化法}

ここでは，局所 1 次元化法について述べる.まず， $z$ 方向磁界から 2 次元 WIM 法により 2 次元電流分布べク トルを求め, 電流ベクトルの $\boldsymbol{x}$ 成分, $y$ 成分を分離する.

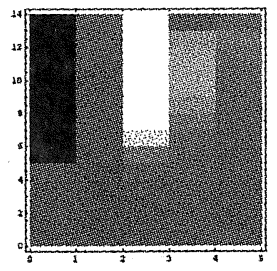

$\mathrm{x}^{*}$ component

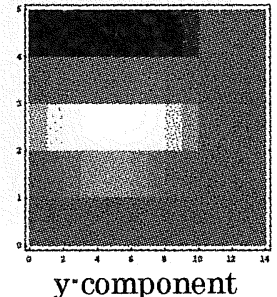

y"component
Fig. 11 Measured magnetic field components in the $\mathrm{x}^{*}, \mathrm{y}^{*}$ directions

次に，電流上を $x$ 方向， $y$ 方向に直線状に測定してゆ き,Fig. 11 に示すそれぞれの磁界から測定線と垂直に流 れる電流を 1 次元 WIM 法により求める. 得られた $x$ 方 向，y方向電流べクトル成分を Fig. 12 に示す.
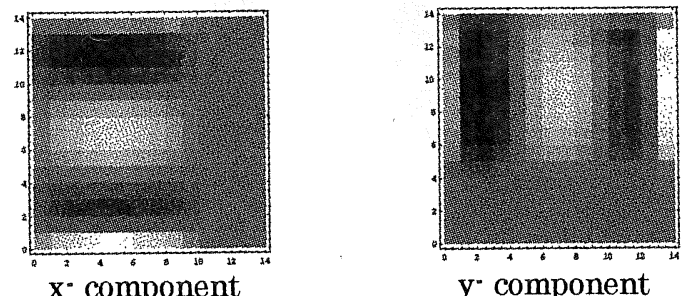

Fig. $12 x^{*}, y^{-}$current vector components by 1D WIM method
Figs. 11 と 12 に示した $x, y$ 成分をそれぞれ畳み込み演 算で共通部分を抽出した結果を, Fig. 13 に示す.

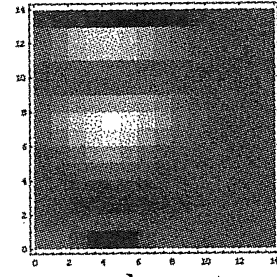

$\mathrm{x} \cdot$ element

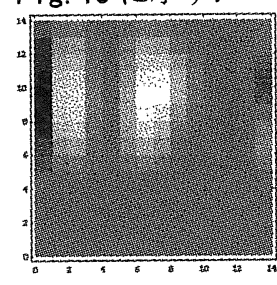

$\mathrm{y}^{*}$ element
Fig. 13 Convolved current components

Fig. 13 の $x, y$ 電流成分をベクトル的に合成し， 2 次元 電流分布を再構成したものが Fig. 14 である.

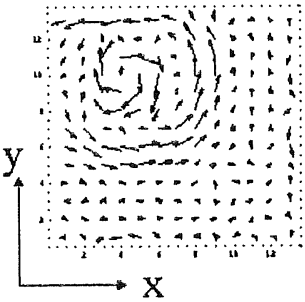

Fig. 14 Composite 2D current distribution

Fig. 14 の結果は, Fig. 9 と比較して, Fig. 5 のモデル コイル形状を詳細に再現していることが解る。これは， $\boldsymbol{x}$ 成分， $y$ 成分をそれぞれ畳み込み演算することによって 電流の存在する箇所のみが抽出されるため, 2 次元 WIM 法単独による結果と比較して, より正確な電流分布が得 られることを意味する.

\section{5。まとめ}

本研究では, $\boldsymbol{z}$ 方向磁界から電流分布を推定する従来 の 2 次元 WIM 法に加えて, $x$ 方向磁界, $y$ 方向磁界を利 用した局所 1 次元化法を提案した，従来の 2 次元 WIM 法では、測定磁界が $z$ 方向成分のみであるため, 詳細な 電流分布を得られない. しかし, 局所 1 次元化法を用い $\tau \boldsymbol{x}$ 方向, $\boldsymbol{y}$ 方向成分の電流分布を推定し, 2 次元 WIM 法と 1 次元 WIM 法で得られた電流成分間の畳み込み演 算で，より詳細な電流分布の推定が可能となった。

\section{参考文 献}

1）高橋広幸：「プリント基板上の電流分布探查に関する研究」 法政大学工学部 2000 年度修士論文。

2) 斎藤兆古著 :「逆問題解析入門」, 法政大学大学院齋藤兆古研 究室講義資料, 2000 年. 